Vittalle - Revista de Ciências da Saúde v. 32, n. 2 (2020) 162-172

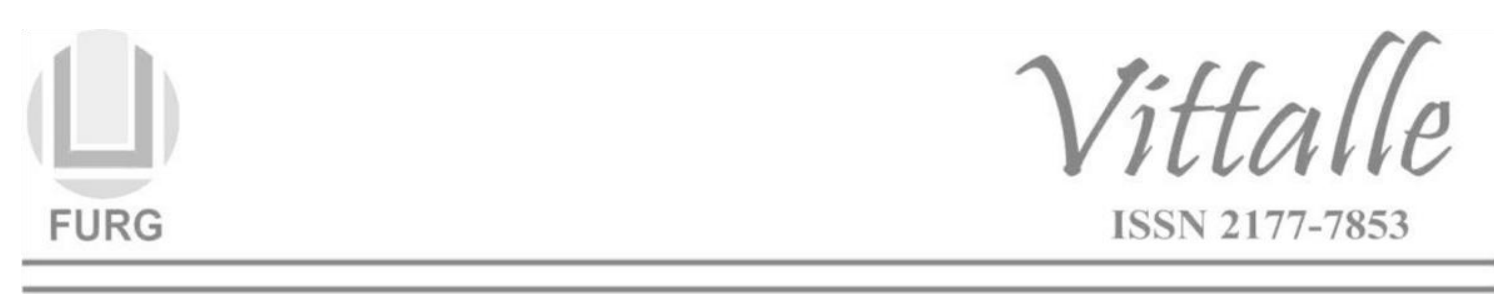

\title{
Desenvolvimento de lideranças em um hospital universitário: um relato de experiência
}

\author{
Daniel Fonseca do Nascimento*, Erivaldo da Silva Santos
}

Universidade Federal do Rio Grande do Norte, Natal, RN, Brasil

Histórico do Artigo
Recebido em:
11/01/2020
Aceito em:
18/04/2020

Palavras-chave: Treinamento; desenvolvimento; gestão em saúde; liderança

\begin{abstract}
RESUMO
As instituições buscam, atualmente, estratégias e novas maneiras de estimular e amadurecer o pensamento crítico-reflexivo dos gestores sobre aprendizagem e gerenciamento de conflitos, visando fortalecer trabalho em equipe, análise e resolução de problemas relacionados à liderança. Este trabalho, trata-se do relato de experiência de um treinamento realizado com gestores, dentro de um Programa de Desenvolvimento de Líderes (PDL) em um Hospital Universitário (HU) do nordeste brasileiro. Nesse contexto, o estudo teve como propósito apresentar pontos importantes como temas, atividades, desafios e benefícios, percorridas as etapas do treinamento. Nesse ínterim, foram utilizadas ferramentas como Matriz SWOT, 5W2H e SIPOC, instrumentos que auxiliaram na identificação e descrição dos processos de trabalho dos profissionais, assim como inclinaram o olhar para as práticas cotidianas, o pensamento estratégico e o foco em resultados, contribuindo para discussões sob o prisma da liderança. Após a experiência de aprendizagem vivenciada, examinou-se, por meio da avaliação de reação, aspectos concernentes ao atendimento das expectativas, nível de obtenção de novos conhecimentos e aplicabilidade do conteúdo à realidade profissional. A pesquisa evidenciou que, $88 \%$ dos participantes apontaram que o treinamento atingiu totalmente as expectativas, tendo ainda $12 \%$ da percepção como alcance parcial. O questionamento sobre a obtenção de novos conhecimentos atingiu $97 \%$ das respostas para os níveis bom ou ótimo, desses, sendo $61 \%$ indicação de grau máximo quanto à retenção do aprendizado. Por fim, para a aplicação do conteúdo à realidade profissional $74 \%$ dos participantes indicaram nível máximo e, somando-se os níveis bom e ótimo se tem um total de $96 \%$ dos resultados nesse item. Assim sendo, a ação configurou-se como subsídio para aculturar os processos de gestão de pessoas, favorecendo a atuação dos líderes e revelando a importância da realização do PDL.
\end{abstract}

\section{Leadership development in a university hospital: an experience report}

\begin{abstract}
Institutions are currently looking for strategies and new ways to stimulate and mature the criticalreflective thinking of managers about learning and conflict management, aiming to strengthen teamwork, analysis and resolution of problems related to leadership. This work is about the experience report of a training carried out with managers, within a Leader Development Program (LDP) in a University Hospital (UH) in northeastern Brazil. In this context, the study aimed to present important points such as themes, activities, challenges and benefits, covering the stages of training. In the meantime, tools such as SWOT Matrix, 5W2H and SIPOC were used, instruments that helped in the identification and description of the professionals' work processes, as well as inclined to look at daily practices, strategic thinking and focus on results, contributing to discussions from the perspective of leadership. After the learning experience, aspects of meeting expectations, the level of obtaining new knowledge and the applicability of content to professional reality were examined by means of reaction assessment. The survey showed that $88 \%$ of the participants pointed out that the training fully met expectations, with $12 \%$ of the perception still being partially reached. The questioning about obtaining new knowledge reached $97 \%$ of the answers for the good or excellent levels, of which $61 \%$ was an indication of a maximum degree regarding the retention of learning. Finally, for the application of the content to the professional reality $74 \%$ of the participants indicated maximum level and, adding the good and excellent levels, there is a total of $96 \%$ of the results in this item. Therefore, the action was configured as a subsidy to acculturate the people management processes, favoring the
\end{abstract} performance of leaders and revealing the importance of carrying out the LDP.

\footnotetext{
*Autor correspondente: daniel20_adm@yahoo.com.br (Nascimento D.F.)
} 


\section{Introdução}

Instituições de todos os portes, públicas ou privadas, de um mercado global ou local já apresentam sinais da percepção de que o investimento em treinamento $\mathrm{e}$ desenvolvimento de pessoas tem se tornado um fator crítico de sucesso, permitindo destaque nesse cenário atual e extremamente competitivo, diferenciando-se sobretudo no quesito liderança. Porém, mesmo sabendo que todos os cargos da organização necessitam, sistematicamente, de atenção quanto ao desenvolvimento, os líderes são notoriamente aqueles que mais precisam se capacitar, uma vez que são peças-chave para condução de qualquer processo de mudança institucional (1).

Quando se estuda liderança, a primeira indagação que vem à mente é: afinal, o que é liderança? Para responder a essa pergunta, necessita-se primeiro entender o que são organizações. Dessa maneira, contribuindo para esse entendimento, toda sociedade humana é composta por organizações responsáveis por fornecer bens tangíveis e intangíveis, que por sua vez, atendem às necessidades da população, através da oferta de serviços como saúde, energia, alimentação, segurança e educação (2), ou seja, elas são incumbidas de munir todos os meios necessários à sobrevivência das pessoas.

Nesse contexto, para que as organizações logrem êxito em suas atividades empresariais, sociais ou familiares, elas necessitam de líderes competentes que sejam capazes de lidar com as adversidades e a complexidade de uma gama de recursos e potencialidades grupais. Essa necessidade, de gerir e liderar, força a organização a buscar, cada vez mais, pessoas aptas à condução e desenvolvimento de equipes com maestria. Assim sendo, a definição de liderança pode ser vislumbrada como, "a capacidade de influenciar um conjunto de pessoas para alcançar metas e objetivos" (3), percebendo-se nitidamente, com base nesta afirmação, que o líder deve ser capaz de inspirar seus liderados, tornando-se elemento essencial à motivação e condução dos processos de trabalho e atividades.

Partindo dessa premissa, as organizações passaram a ofertar Programas de Desenvolvimento de Líderes (PDL), estes, despontam de maneira crescente e comumente mais valorizados no âmbito corporativo. Semelhantemente, reforçando essa linha de pensamento, as organizações modernas estão, manifestamente, preocupadas em direcionar seus investimentos à formação humana, levando em consideração benefícios mútuos para empresa e colaborador (4). Nessa ótica, as organizações bem-sucedidas investem massivamente em Treinamento e Desenvolvimento (T\&D), com isso, entregam mais valor aos clientes e possibilitam o retorno garantido de desembolsos financeiros (5).

Não obstante, muitas empresas vislumbram essa realidade e acreditam no papel imprescindível que a liderança exerce sobre todas as pessoas da organização, influenciando diretamente em processos de trabalho e resultados institucionais. No mercado atual "a demanda por liderança excede em muito a oferta" (6) e, mesmo com todo o conhecimento e energia empregados na promoção e desenvolvimento de novos líderes, carece ainda mais da formação de novos talentos, munidos de competências indispensáveis as suas práticas e responsabilidades, daí a grande necessidade de se capacitar nesse enfoque de atuação organizacional.

Nessa perspectiva, a realização de um PDL estruturado para formação humana com temas sobre liderança, torna-se primordial à medida que prepara gestores para a complexa missão de liderar, inserindo-os em uma experiência de construção e amadurecimento de conhecimentos e habilidades essenciais à atuação profissional. Assim sendo, o presente trabalho busca explicitar, a partir deste relato, o percurso de um 
treinamento para gestores de um Hospital Universitário (HU) do nordeste brasileiro, apresentando temas, atividades, desafios, benefícios e pontos importantes à prática de um líder, percorridas as etapas de uma experiência de aprendizagem, ou seja, diagnóstico, desenho, implementação e avaliação.

\section{Materiais e Métodos}

Este relato de experiência teve como alicerce a pesquisa descritiva exploratória, a qual visa descrever situação ou contexto em busca de mais informações durante a investigação e explorar as suas características, fenômenos e resultados, possibilitando dessa maneira, a compreensão dos eventos (7).

Como estratégia de investigação, empregou-se o método qualitativo, que permite "estabelecer o significado de um fenômeno a partir do ponto de vista dos participantes" e da observação do comportamento, podendo ainda, o pesquisador, examinar uma questão relacionada à inquietação de determinados indivíduos (8). A "abordagem qualitativa aprofunda-se no mundo dos significados das ações e relações humanas" (9), e tem como objetivo entender de forma mais aprofundada os elementos envolvidos (10).

Nessa ótica, o estudo possibilitou exploração e descrição da atuação dos participantes durante o treinamento, diante dos temas abordados e do propósito educacional, dando aporte à análise da contribuição às práticas cotidianas dos profissionais envolvidos, na condição de objeto deste estudo.

Ressalta-se que, antes de se realizar o treinamento, foi elaborado um questionário para auxiliar o Diagnóstico de Necessidades de Treinamento (DNT), importante instrumento para aumentar as possibilidades de análise e interpretação dos níveis de competência dos colaboradores, trazendo à luz fatos e dados novos que apoiaram a construção da ação e deste estudo (1).

Assim sendo, o DNT teve como finalidade aprofundar o conhecimento acerca das reais lacunas a serem trabalhadas no PDL, contribuindo com o alinhamento de competências gerenciais e organizacionais. Vale acentuar que, essa última "é o resultado de uma combinação estratégica de recursos, habilidades e processos organizacionais, os quais são orientados e integrados para o atendimento de uma ou mais necessidades dos clientes" (11).

Salienta-se que, o PDL implantado pelo HU teve início no ano de 2017, sendo realizado em dois momentos, o primeiro entre os meses de abril e junho de 2017, o segundo entre os meses de setembro e novembro do mesmo ano, onde participaram respectivamente 41 e 46 profissionais da saúde atuantes nas áreas médica, assistencial e administrativa, mesclados, sem distinção de níveis ou área de atuação. Destaca-se que, os momentos de aprendizagem aconteceram em horário de trabalho, no turno da manhã, com gestores formais e informais, tendo prioridade para participação ocupantes de cargo de chefia, seguidos por outros profissionais de significativa influência organizacional das gerências de Atenção à Saúde, Ensino e Pesquisa e Administrativa, convocados por seus respectivos gerentes, possibilitando assim maior adesão, excetuando-se apenas casos como atestado médico ou licença programada.

É importante ressaltar que o treinamento foi realizado no contexto de um Programa de Desenvolvimento de Líderes, no Campus Central de uma Universidade Federal do nordeste brasileiro, sendo ministrado por um administrador e uma psicóloga, com temas relacionados à liderança. Na ocasião, dentre os participantes havia a presença de um pedagogo acompanhando e avaliando o desenvolvimento de cada módulo.

No que tange à estrutura do treinamento, enfoca-se que este foi dividido em 7 módulos, com encontros semanais, conforme denota a Figura 1. Cada módulo com 04 
horas de duração, totalizando assim carga horária de 28 horas, onde todos os temas foram alinhados e desenhados de acordo com as necessidades apontadas pelo diagnóstico prévio. Cada encontro foi subdivido em duas seções, a primeira, abordou a teoria por meio de exposição dialogada, ao passo que a seguinte reforçou o conteúdo ministrado com atividades práticas. Entre elas, destacaram-se estudos de caso, dinâmicas de grupo, atividades gamificadas, dramatizações e construções compartilhadas.

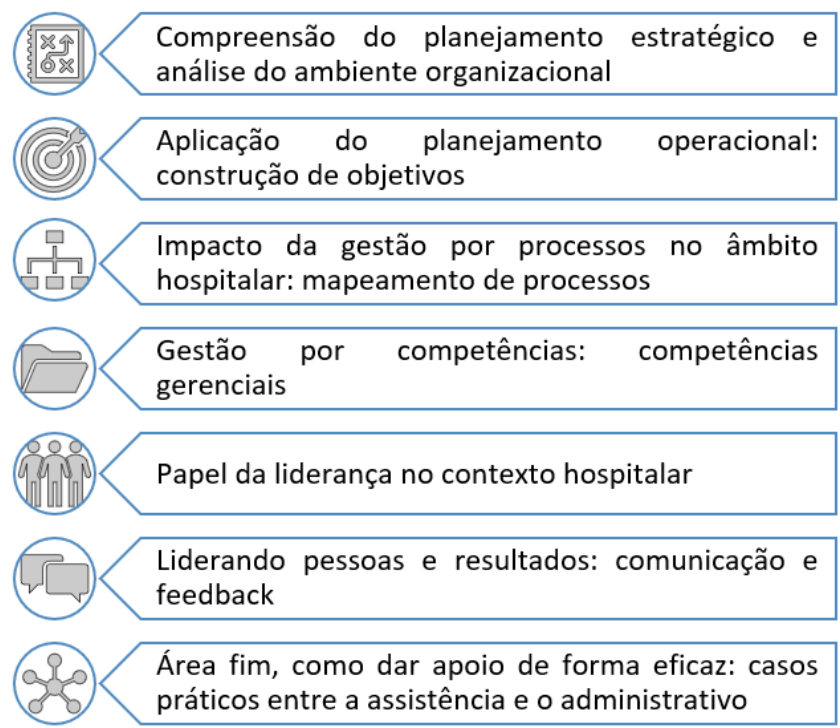

Figura 1 - Módulos do treinamento.

Com a finalidade de provocar estímulo à liderança, durante a condução das atividades práticas, cada grupo elegeu um representante, o líder, para expor e defender o ponto de vista discutido entre eles, correlacionando o tema e o papel do líder no contexto da saúde e da unidade hospitalar.

Diante dessa realidade, na perspectiva de evidenciar a melhor performance dos participantes, a realização do treinamento percorreu as quatro etapas de um processo de treinamento, ou seja, diagnóstico, desenho, implementação e avaliação (2), conforme percebe-se na Figura 2.

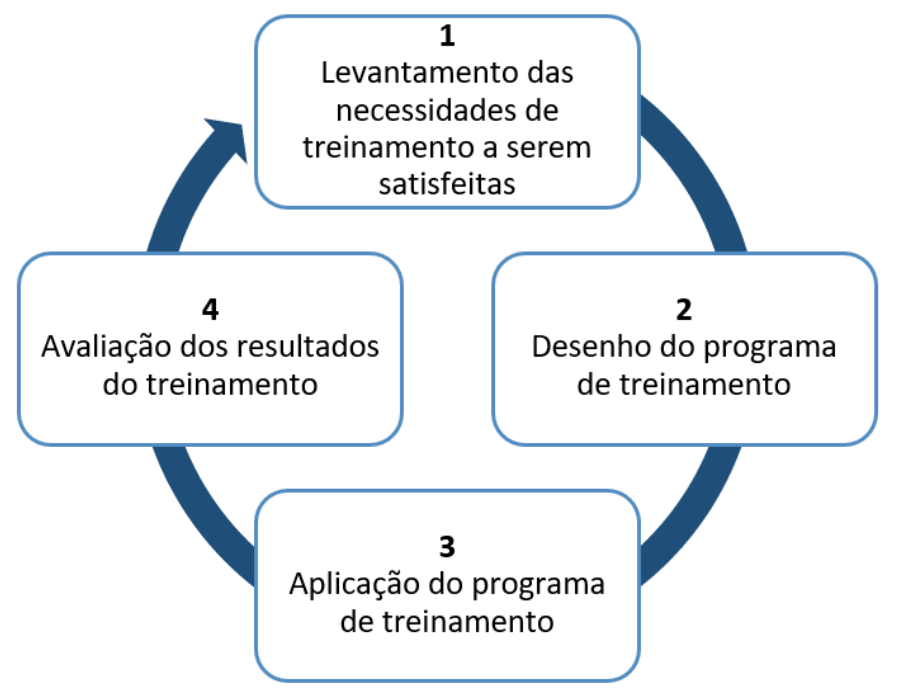

Figura 2 - As quatro etapas do processo de treinamento. Fonte: Chiavenato (2). 
Nesse decurso, pensando estrategicamente, foram utilizadas ferramentas como Matriz SWOT, 5W2H e SIPOC, elementos de apoio à identificação e descrição dos processos de trabalho dos participantes, contribuindo para enriquecer a dinâmica de realização das atividades propostas e as discussões geradas sobre as práticas cotidianas dos gestores.

O processo avaliativo se propôs a encontrar respostas sobre aspectos como atendimento das expectativas com o treinamento, nível de obtenção de novos conhecimentos e aplicabilidade do conteúdo à realidade profissional. Para tanto, não havia a necessidade do participante se identificar. Frisa-se que, apesar de não estar explícito neste trabalho, com o instrumento avaliativo investigou-se ainda questões como adequação do conteúdo ao treinamento, equilíbrio entre teoria e prática, pontos relacionados à atuação dos instrutores, infraestrutura e logística. Informações essas, que poderão ser usadas para avaliar e aperfeiçoar os futuros processos de formação humana na instituição.

Faz-se necessário sublinhar que, para melhor ambientação, outras ações fazem parte do PDL, além do treinamento investigado neste trabalho. Nos anos seguintes, o Programa teve continuidade com a realização de treinamentos para mais 03 turmas, nos meses de março e abril de 2019, abordando temas como autoconhecimento, comunicação, relacionamento interpessoal, gestão do tempo, produtividade, gestão e liderança, proporcionando a participação de 120 colaboradores do HU. Importa destacar que, em sequência, está prevista para 2020 a terceira experiência de aprendizagem dentro desse Programa, tendo em seu projeto básico, já definido, conteúdos como experiências gamificadas sobre influência e produtividade, comunicação e feedback, competências comportamentais e avaliação de resultados.

Por fim, reforça-se que, a pesquisa foi realizada através de procedimentos de observação e aplicação de questionário, instrumentos elaborados e técnicas selecionadas a fim de efetivar a coleta e exploração dos dados previstos, consolidando o estudo (12). Ademais, vale realçar que a análise das informações obtidas com o questionário, coleta realizada no período de 15 de dezembro de 2017 à 12 de janeiro de 2018, embasada no acompanhamento dos módulos, apresenta dados genuínos e imprescindíveis para entendimento dos resultados e discussão.

\section{Resultados e discussão}

\section{Contextualização e fundamentação}

O processo de construção do treinamento, foco deste estudo, levou em consideração as bases da liderança, com a intenção de promover a sintonia entre PDL e a continuidade da lógica do pensamento, que norteia o comportamento de um líder e sua prática, utilizando-se das principais abordagens da liderança presentes na literatura, seguindo determinada sequência, conforme se observa na Figura 3. 


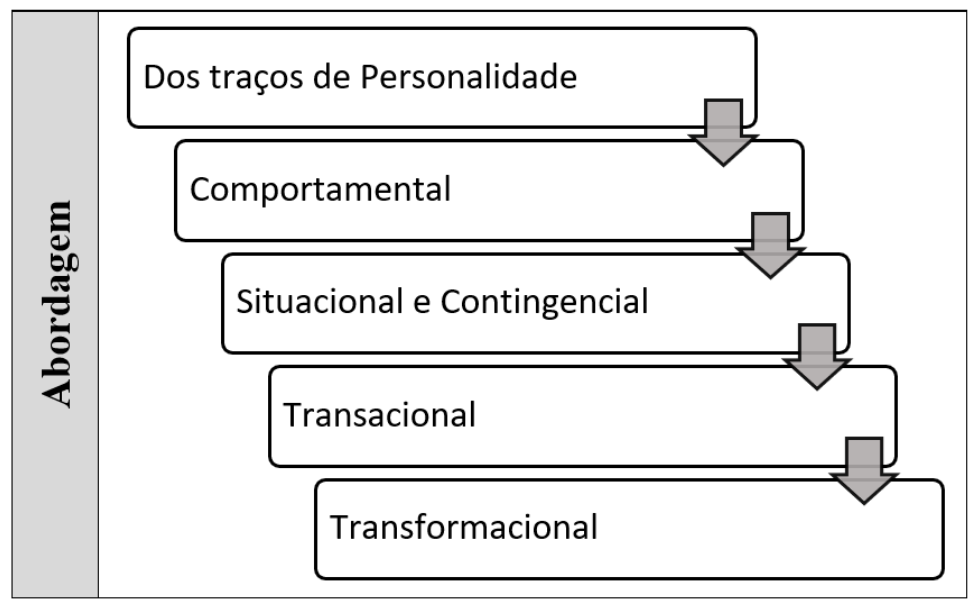

Figura 3 - Principais abordagens da liderança.

Nesse universo, associado à liderança, averiguou-se também um dos aspectos mais relevantes da área de gestão, que são as pessoas, responsáveis pelo pleno funcionamento da dinâmica institucional.

Assim sendo, face à evolução das principais teorias da liderança, no decorrer da história, bem como à importância do treinamento e do desenvolvimento para pessoas e instituições, resta-se interpretar a influência que o líder exerce sobre seus liderados e correspondente progresso intelectual. Essa é uma tarefa complexa e não linear, além de necessitar rigorosamente da presença de um líder facilitador, com inteligência emocional e equilíbrio, no decorrer das jornadas laboral e educacional, uma vez que a liderança está associada às interações sociais e, consequentemente, à influência que uma pessoa exerce sobre a outra, implicando na forma como as decisões são tomadas em uma organização, quando considerados valores, crenças e significados compartilhados (13).

Em visão contínua, a área de Gestão de Pessoas deve estar preparada para capacitar tanto os colaboradores internos quanto os de fora da organização que exercem, de maneira direta ou indireta, influência na qualidade dos produtos ou serviços institucionais (14). À vista disso, treinamentos e programas para o desenvolvimento de competências devem ser definidos e ajustados de acordo com a necessidade da organização e seus projetos, traçando-se determinadas trilhas de aprendizagem para o desenvolvimento dos envolvidos, tornando-os mais produtivos, criativos e inovadores (15).

Todavia, o treinamento é um esforço de melhora individual e, apesar de ser imprescindível, hoje, se torna insuficiente para as necessidades organizacionais em um mundo completamente instável (2), o novo modelo de gestão, busca relacionar as competências das pessoas com a estratégia organizacional e com os processos de aprendizagem, adaptando-se à transformação de significados, às condições de trabalho e ancorando-se diferencialmente na preparação de profissionais contemporâneos e futuros (16).

Nessa conjuntura, para suprir lacunas de competência é vital ir além do treinamento, é necessário que as instituições desenvolvam plenamente seus profissionais. Diante desse diferencial, cabe salientar que, treinar e desenvolver pessoas não é a mesma coisa, enquanto o primeiro evidencia o presente, buscando aprimorar o desempenho imediato do cargo, o desenvolvimento focaliza o futuro, provendo as pessoas de competências que serão requeridas mais à frente (2). Nessa perspectiva, na Figura 4, pode-se perceber que os processos de desenvolvimento são compostos de três camadas superpostas: treinamento, desenvolvimento de pessoas e desenvolvimento organizacional (2). 


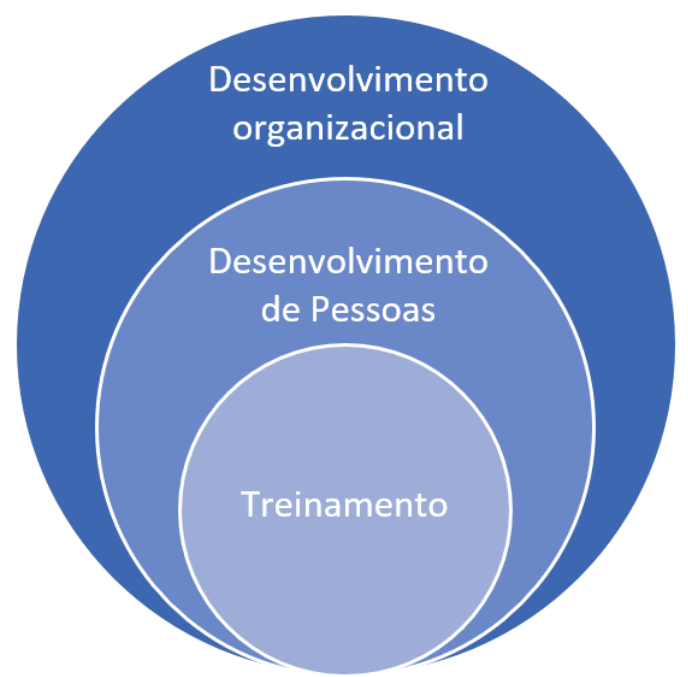

Figura 4 - Camadas do processo de desenvolvimento. Fonte: Adaptado de Chiavenato (2).

Desse modo, apesar da diferença conceitual, treinamento e desenvolvimento constituem processos educacionais, tendo a aprendizagem como uma mudança no comportamento da pessoa, pela incorporação de novos hábitos, conhecimentos, destrezas e atitudes (2). Esses processos juntos envolvem o conhecimento explícito, que é o conhecimento formal sistêmico exigido nos treinamentos corporativos e agrega o conhecimento tácito, compreendido como um saber arraigado à abstração pessoal, às experiências, à visão de mundo e às práticas cotidianas, mobilizando estratégias e raciocínios complexos capazes de gerar a ação necessária em um contexto específico (16).

\section{Implementação do treinamento}

O ambiente de aprendizagem, no qual os líderes do HU foram inseridos, por se tratar de um treinamento parte de um programa maior, pautou-se principalmente na concepção voltada ao desenvolvimento de pessoas, questão estratégica para qualquer organização, especialmente em virtude de seus resultados serem reflexo da conduta de seus líderes, assim como, partindo do princípio de que, o líder deve traçar o caminho e inspirar uma visão compartilhada e desafiadora do processo, capacitando sua equipe para a ação e o encorajamento (17).

Em tal situação, além do líder ser o porta voz da cultura e das aspirações da empresa (18), ele corresponde ao principal fator de influência no desempenho das atividades, propiciando retorno positivo, de fundamental importância, tendo em vista a relevância do seu papel para o alcance das metas da organização (19). Os autênticos líderes são positivos, éticos, orientados por valores, colaborativos e ao exibir esses comportamentos, conquistam a confiança, o respeito e influenciam o desempenho dos seus liderados. Atualmente na área da saúde não é diferente, nesse ambiente cada vez mais dinâmico e complexo, os líderes são chamados a manter um atendimento de qualidade aos usuários dos serviços oferecidos, controlando custos e apoiando as metas organizacionais (20).

Nesse contexto e, tendo em vista que a maior parte do corpo profissional de um HU é composto pela enfermagem, vale enfatizar que, muitas organizações já identificaram as competências relacionadas ao treinamento e desenvolvimento de lideranças na enfermagem, possíveis de se aplicar a outras áreas, estruturando-as em três domínios: O Líder Interno, que foca na responsabilidade pessoal e profissional, planejamento de carreira, disciplinas de jornada pessoal e liderança de si mesmo, por meio da reflexão. A 
Ciência da Liderança, abordando as gestões financeira, de pessoas e estratégica, melhoria de desempenho, habilidades de pensamento, tecnologia e conhecimento da prática. A Arte da Liderança, domínio formado pelas habilidades de liderar pessoas, comportamentos de relacionamento e influência, diversidade e tomada de decisão compartilhada (21).

Acentua-se que, o desenvolvimento de lideranças nas instituições é, em primeiro lugar, um alvo educacional (22), que deve ser direcionado para o desenvolvimento de competências essenciais para liderar. Alinhando-se a esse propósito, apresenta-se na sequência análise de dados, onde, o Gráfico 1, destaca o percentual de satisfação de atendimento das expectativas dos participantes com relação ao treinamento, esboçandose, de modo geral, o nível de percepção dos líderes com relação a esse aspecto.

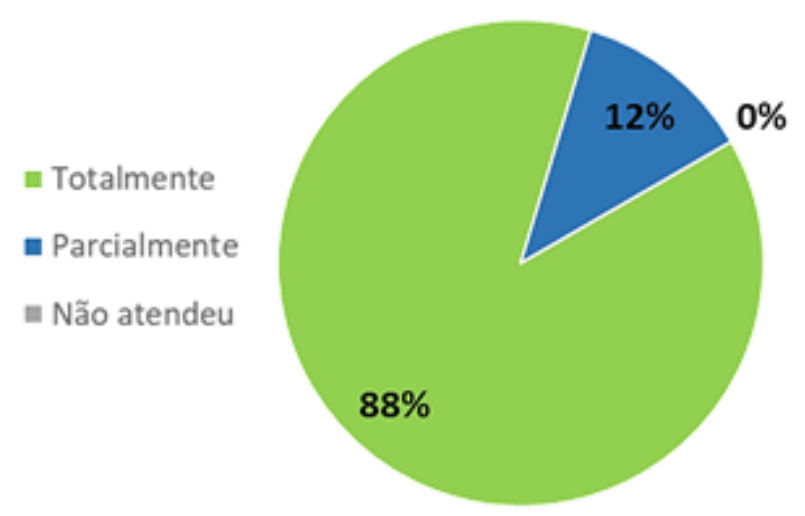

Gráfico 1 - Atendimento das expectativas do treinamento.

Pontua-se que, a partir da análise dos objetivos de aprendizagem e das informações coletadas com o questionário de pesquisa, em específico os resultados para esse item, $88 \%$ dos participantes apontaram que o treinamento atingiu totalmente as expectativas, tendo ainda $12 \%$ da percepção como alcance parcial. Indo além, pode-se concluir com esses dados, que $100 \%$ das respostas indicaram êxito total ou parcial, ou seja, do ponto de vista dos participantes a ação foi bem-sucedida.

No Gráfico 2, é possível identificar o nível de obtenção de novos conhecimentos, possibilitando, por meio do questionamento realizado, o fortalecimento da hipótese de que o desenvolvimento de gestores é fundamental à formação de lideranças, consequentemente, benéfica à instituição, diante da imensa responsabilidade de educar, desenvolver pessoas e prestar serviços de qualidade.

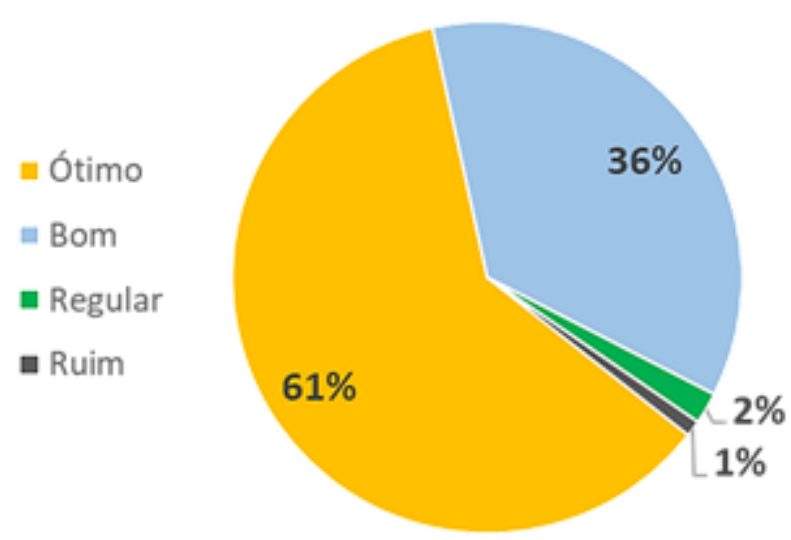

Gráfico 2 - Nível de obtenção de novos conhecimentos 
Tratando-se ainda do Gráfico 2, como resultado à indagação, os participantes consideraram os níveis bom ou ótimo, confirmando a construção de novos conhecimentos, tendo a maioria, $61 \%$, indicado grau máximo quanto à retenção do aprendizado e 36\% grau 3, em uma escala de 1 a 4 . Esses dados representam, significativamente, $97 \%$ das respostas dos participantes, reforçando-se a eficácia do treinamento.

No que se refere às informações sobre a relação entre a aplicabilidade do conteúdo ministrado e a realidade profissional dos gestores, aproximadamente, 3 a cada 4 participantes julgaram que o aprendizado adquirido com o treinamento se aplica às práticas cotidianas. Vale realçar que, considerando-se as variáveis 'Ótimo' e 'Bom', soma-se $96 \%$ dos resultados obtidos nesse item, conforme se observa no Gráfico 3.

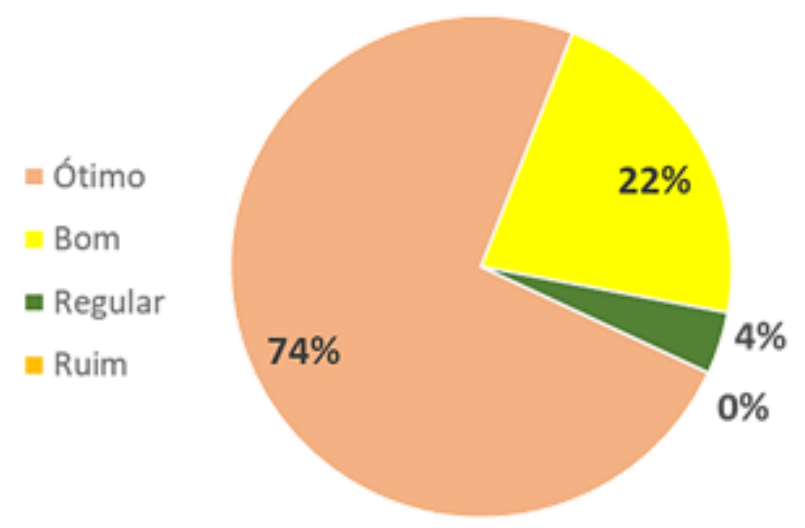

Gráfico 3 - Aplicabilidade do conteúdo à realidade profissional

Logo, esses dados sugerem um impacto iminente na mudança de comportamento dos líderes e, como espelho, vislumbra-se a melhoria da produtividade e da qualidade dos serviços de saúde prestados à população. A investigação possibilitou ainda a identificação dos prováveis desafios e benefícios vislumbrados acerca do treinamento e do Programa como um todo, os quais são discriminados no Quadro 1.

Quadro 1 - Desafios e benefícios do PDL

\begin{tabular}{|c|c|}
\hline DESAFIOS & BENEFÍCIOS \\
\hline $\begin{array}{l}\checkmark \quad \text { Manter o PDL de forma contínua e } \\
\text { sistemática. }\end{array}$ & $\begin{array}{l}\checkmark \quad \text { Desenvolvimento de competências } \\
\text { fundamentais e gerenciais. }\end{array}$ \\
\hline $\begin{array}{l}\checkmark \quad \text { Realizar novos treinamentos dentro do } \\
\text { Programa. }\end{array}$ & $\begin{array}{l}\checkmark \text { Fortalecimento de atitudes das lideranças } \\
\text { formais e informais. }\end{array}$ \\
\hline $\begin{array}{l}\checkmark \text { Disponibilizar o Programa para todas as } \\
\text { lideranças formais e informais do HU. }\end{array}$ & $\begin{array}{l}\checkmark \quad \text { Possibilidade de aumento da sinergia e } \\
\text { engajamento entre líder e liderado. }\end{array}$ \\
\hline $\begin{array}{l}\checkmark \quad \text { Aprimorar infraestrutura e logística do } \\
\text { treinamento. }\end{array}$ & $\begin{array}{l}\checkmark \quad \text { Melhoria na comunicação vertical e } \\
\text { horizontal. }\end{array}$ \\
\hline $\begin{array}{l}\checkmark \text { Acompanhar os líderes, em suas práticas, } \\
\text { após os treinamentos. }\end{array}$ & $\begin{array}{l}\checkmark \quad \text { Possibilidade de autoavaliação e otimização } \\
\text { de feedbacks. }\end{array}$ \\
\hline
\end{tabular}

Nesse contexto, faz-se oportuno revelar que, esta pesquisa não pretende esgotar o estudo sobre o tema ou opinar categoricamente quanto à eficácia do treinamento. Reconhecendo-se, desta forma, a importância da realização de estudos mais aprofundados, que avaliem aspectos além dos destacados neste trabalho, como planejamento estratégico, clima e cultura organizacional, avaliação de desempenho e desenvolvimento de competências gerenciais como tomada de decisão, gestão compartilhada, gestão em equipe multiprofissional, representação institucional, 
planejamento participativo e outras.

Frente ao exposto, o estudo pode ser visto como um instrumento auxiliar para o aprimoramento do PDL e de futuros treinamentos, pontuando-se a relevância da continuidade do Programa nos anos seguintes e impulsionando os atuais e futuros líderes da instituição, dotando-os de conhecimentos e habilidades, bem como fortalecendo atitudes indispensáveis ao bom desempenho de suas funções, dando atenção especial às maneiras de incentivar o diálogo reflexivo e desenvolver mecanismos apropriados para avaliar os resultados, que se expandem para além do desenvolvimento de competências (23).

\section{Considerações Finais}

A capacidade das pessoas em aprender e desenvolver suas potencialidades, seja no aspecto pessoal ou profissional é indiscutível e quando o assunto é treinamento e desenvolvimento muitas instituições já entenderam o seu real significado, investindo em formação humana com o propósito de preparar seus talentos para os desafios que este século traz em seu bojo. Na área da saúde não é diferente, nesse ambiente cada vez mais dinâmico e complexo é preciso formar pessoas críticas, comprometidas e sobretudo que saibam liderar suas equipes, permitindo inovar os processos e práticas cotidianas requeridas, principalmente, em um ecossistema hospitalar.

Nessa vertente, os resultados deste estudo mostram que o treinamento realizado possibilitou aos participantes vivenciar novas experiências interativas e reflexivas, consubstanciando a expectativa de mudança de comportamento e de inovação das práticas gerenciais, além disso, caracterizou-se como excelente meio de desenvolvimento e campo fértil para semear novos pensamentos e condutas para atuais e futuros gestores organizacionais.

Finalmente, este trabalho apresenta dados que estão em consonância com achados da literatura, destacando desafios, benefícios e outros pontos relevantes vivenciados em uma experiência de aprendizagem e revela a importância da realização de programas de liderança, especialmente em instituições inseridas no contexto da saúde. Dessa maneira, acentua-se a necessidade de se realizar futuros estudos para descrever ações e estratégias que seguem ao longo do PDL, na busca por mais resultados, benefícios e respostas que não foram contempladas nesta pesquisa.

\section{Referências}

1. Madruga R. Treinamento e Desenvolvimento com foco em Educação Corporativa. São Paulo: Saraiva Educação, 2018.

2. Chiavenato I. Gestão de pessoas: e o novo papel dos recursos humanos nas organizações. 4. ed. Barueri: Manole, 2014.

3. Charan R, Drotter S, Noel J. Pipeline de liderança: O desenvolvimento de líderes como diferencial competitivo. São Paulo: Elsevier, 2018.

4. Maximiano ACA. Introdução à Administração. 7. ed. rev. e ampl. São Paulo: Atlas, 2009.

5. Robbins SP. Comportamento organizacional. 14. ed. São Paulo: Prentice Hall, 2010.

6. Dutra JS. Gestão de Pessoas: modelo, processos, tendências e perspectivas. 2. ed. São Paulo: Atlas, 2016.

7. Fachin O. Fundamentos de metodologia. 4. ed. São Paulo: Saraiva, 2003.

8. Creswell JW. Projeto de Pesquisa: métodos qualitativo, quantitativo e misto. Porto Alegre: Artmed Bookman, 2007.

9. Minayo MCS. (Org.). Pesquisa Social: teoria, método e criatividade. Petrópolis, RJ: Vozes, 2003.

10. Prodanov CC, Freitas EC. Metodologia do trabalho científico: métodos e técnicas da pesquisa e do 
trabalho acadêmico. 2. Ed. Editora Feevale. 2013.

11. Hanashiro DMM et al. Gestão do Fator Humano: uma visão baseada em stakeholders. 2. ed. rev. e ampl. São Paulo: Saraiva, 2008.

12. Lakatos EM, Marconi MA. Fundamentos de metodologia científica. 8. ed. São Paulo: Atlas, 2019.

13. Moscardini TN, Klein A. Educação Corporativa e desenvolvimento de lideranças em empresas multisite. Revista de Administração Contemporânea 2015; 19(1): 84-106.

14. Gil AC. Gestão de Pessoas: enfoque nos papéis estratégicos. 2. ed. São Paulo: Atlas, 2019.

15. Castro ABC, Brito LMP, Varela JDS. A ressignificação da área de gestão de pessoas e os novos papéis das pessoas e das organizações. Holos 2017; 4, 408-423.

16. Assunção YB, Goulart IB. Qualificação Profissional ou Competências para o Mercado Futuro? Future Studies Research Journal: Trends \& Strategies 2016; 8(1): 175-207.

17. Kouzes JM, Posner B. O Novo Desafio da Liderança: A Fonte Mais Confiável para Quem Deseja Aperfeiçoar Sua Capacidade de Liderança. São Paulo: Campus, 2008.

18. Carvalhal E, Ferreira G. Ciclo de vida das organizações: peopleware, liderança transformadora, desenvolvimento de equipes de alto desempenho. 5. Ed. Rio de Janeiro: FGV Editora, 2001.

19. Almeida MM. A escassez de líderes no mercado de trabalho: o papel do professor universitário na formação deste profissional pode colaborar para a mudança do cenário atual. Gestão \& Sociedade: Revista de Pós-Graduação da Uniabeu 2012; 1(1).

20. Frasier N. Preparing nurse managers for authentic leadership: A pilot leadership development program. JONA: The Journal of Nursing Administration 2019; 49(2): 79-85.

21. Ramseur P, Fuchs MA, Edwards P, Humphreys J. The implementation of a structured nursing leadership development program for succession planning in a health system. JONA: The Journal of Nursing Administration 2018; 48(1): 25-30.

22. Guimarães JL. Mandar é fácil, difícil é liderar: o desafio do comando na nova economia. Salvador: Casa da Qualidade, 2001.

23. Clapp JT, Gordon EK, Baranov DY, Trey B, Tilin FJ, Fleisher LA. Encouraging reflexivity in a residency leadership development program: Expanding outside the competency approach. Academic Medicine 2018; 93(2): 210-213. 